\title{
ROCKET PROTOTYPE OF AN X-RAY OPTICAL SYSTEM FOR SURVEYING AND LOCATING COSMIC X-RAY SOURCES
}

\author{
P. C. FiShER, L. W. ACTON, R. C. CATURA, P. KIRKPATRICK, \\ A. J. MEYEROTT, and D. T. ROETHIG \\ Lockheed Palo Alto Research Laboratory, Palo Alto, Calif., U.S.A.
}

The characteristics of an X-ray detection system based on an array of parabolic reflectors that provide a line-shaped focus will be described. The most recent rocket instrument has an overall length of about two meters and utilizes a pair of thinwindow gas-flow proportional counters for detecting the X-rays. The variation of effective aperture with X-ray energy, the amount of scattering from the mirror surfaces, and the quality of the optical focus will be discussed. Estimates of the sensitivity of a larger set of X-ray optics used as a survey system, and when combined with a special grating to form a spectrograph, will be presented.

This program has been carried out under the support of the National Aeronautics and Space Administration (Contracts NASw-909, 917, and 1388) and the Lockheed Independent Research Program.

\section{DISCUSSION}

E. A. Trendelenburg: Is it intended to fly your experiment on a satellite?

P.C. Fisher: An experiment involving a pair of mirror arrays, and including a spectroscopic capability has been proposed for satellite use. 